Portland State University

PDXScholar

\title{
A Comparison of the Effects of Paced Practice and Progressive Practice Skillbuilding Procedures on the Development of Straight-Copy Speed and Accuracy in Beginning Collegiate Typewriting
}

Bonnie Sue Shannon

Portland State University

Follow this and additional works at: https://pdxscholar.library.pdx.edu/open_access_etds

Part of the Business Commons, and the Education Commons

Let us know how access to this document benefits you.

\section{Recommended Citation}

Shannon, Bonnie Sue, "A Comparison of the Effects of Paced Practice and Progressive Practice Skillbuilding Procedures on the Development of Straight-Copy Speed and Accuracy in Beginning Collegiate Typewriting" (1980). Dissertations and Theses. Paper 3498.

https://doi.org/10.15760/etd.5381

This Thesis is brought to you for free and open access. It has been accepted for inclusion in Dissertations and Theses by an authorized administrator of PDXScholar. Please contact us if we can make this document more accessible: pdxscholar@pdx.edu. 
A COMPARISON OF THE EFFECTS OF PACED PRACTICE AND PROGRESSIVE PRACTICE SKILLBUILDING PROCEDURES ON THE DEVELOPMENT OF STRAIGHT-COPY SPEED AND ACCURACY IN BEGINNING COLLEGIATE TYPEWR I I ING

\author{
by \\ Bonnie Sue Shannon
}

Professional Paper

Submitted in Partial Fulfillment of the Requirements

for the MST Degree in Business Education

\author{
Portland State University \\ Dr. Leonard Robertson, Advisor \\ April 28, 1980
}




\section{ACKNOWLEDGMENTS}

The writer extends sincere appreciation to the following individuals who have contributed to this research project:

Mrs. Karel Pollard, Instructor, Department of Business Education, Portland State University, for her invaluable moral support and continued interest in the improvement of typewriting instruction.

Dr. Leonard Robertson, Head, Department of Business Education, Portland State University, for stimulating and sustaining my interest in experimental research and for his continued support, encouragement and assistance in conducting and reporting the research. A special thank you is given to him for permitting my use of Dr. West's textbook in PSU's typewriting classes which was necessary in order to conduct the research.

Dr. Leonard J. West, Professor, Baruch City College, New York City, for his unlimited enthusiasm and expertise in the areas of typewriting and research, and for his interest, advice and faith in the research of a novice. 
APPRO VED :

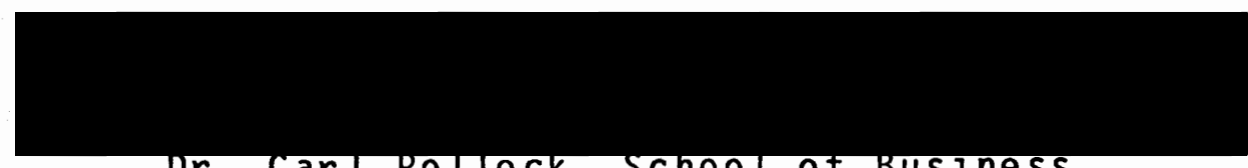

or. carlpollock, School ot business

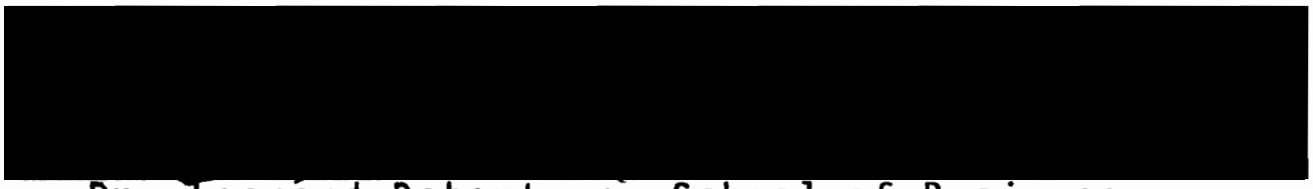

Or. Leonard Robertson, School of Business

Ur. Forbes Williams, School of Education

Date Presented May $14 / 980$ 
List of Tables

CHAPTER 1 INTRODUCTION

Need for the Study . . . . . . . . . . 2

Statement of the Problem ........... 3

Purpose . . . . . . . . . . . . . . 3

Delimitations and Limitations........ 4

Definition of Terms ............. . 5

Summary .................. 6

CHAPTER 2 REVIEW OF RELATED LITERATURE

Introduction..$\cdot \cdot \cdot \cdot \cdot \cdot \cdot \cdot \cdot \cdot \cdot \cdot \cdot \cdot 7$

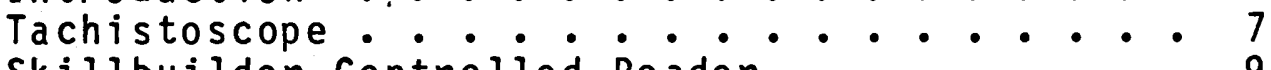

Skillbuilder Controlled Reader . . . . . . . . 9

Strong Pacer ................. 11

Other Mechanical Devices ......... 13

Summary . . . . . . . . . . . . . 14

CHAPTER 3 METHODS AND PROCEDURES

Se lection of the Subjects . . . . . . 15

Research Techniques ............. 16

Description of Treatments . . . . . . . 18

Duration of Treatments . . . . . . . . 22

Description of Materials ......... 25

Testing .................. 26

Treatment of the Data........... 26

Summary . . . . . . . . . . . . . 27

CHAPTER 4 FINDINGS, CONCLUSIONS AND RECOMMENDATIONS

Findings . . . . . . . . . . . . 28

Conclusions: . . . . . . . . . . . 35

Recommendations............. 36

APPENDIX

1 Rationale for Practice and Procedures . . 38

2 Sample Practice Materials ....... 40

3 Sample Practice Schedules ........ 42

4 Error Allowance Chart--Paced Practice.. 43

5 Test Timings--Pretest and Posttest . . . 44

6 Straight-Copy Me asurement Procedures . . . 48 


\section{LIST OF TABLES}

Table 3-1: Study Timetable

Table 3-2: Durations of Timings for Progressive Practice

Table 3-3: Durations of Timings for Paced Practice.

Table 4-1: Individual Pre- and Posttest Speed and Accuracy Scores and Minutes of Practice--Paced Practice Group

Table 4-2: Individual Pre- and Posttest Speed and Accuracy Scores and Minutes of Practice--Progressive Practice Group

Table 4-3: Measures of Central Tendency and Distribution of Pre- and Posttest Speed Scores--Paced Group

Table 4-4: Measures of Central Tendency and Distribution of Pre- and Posttest Speed Scores--Progressive Group

Table 4-5: Measures of Central Tendency and Distribution of Pre- and Posttest Accuracy Scores--Paced Group

Table 4-6: Measures of Central Tendency and Distribution of Pre- and Posttest Accuracy Scores--Progressive Group 


\section{CHAPTER 1 INTRODUCTION}

Typewriting has become a generally used skill in many occupations and for a variety of personal uses. Enrollments in typewriting classes at the high school and collegiate levels are high. Personal use of the typewriter outweighs vocational use as a reason for enrolling in a typewriting class. As a result, students are usually enrolled in a class of one-year duration or less. This short period of training time indicates the need for efficient instructional methods that will develop the maximum proficiency in the minimum amount of time.

In some instances, a beginning college-level typewriting class allows for only ten to twelve weeks of training. A considerable portion of this time is devoted to the building of straight-copy stroking skills. Teachers are continuously searching for better methods to develop speed and accuracy of straight-copy typewriting. In addition, teachers disagree as to the superiority of the differing methods and materials advocated by the authors of available typewriting textbooks.

The text, Modern College Typewriting--A Basic Course, by Dr. Leonard J. West, includes a comprehensive straight-copy skillbuilding program incorporating his philosophy of teaching typewriting. The program in his text contains materials for paced and progressive practice. Dr. West presents research datal in his book, Acquisition of Typewriting Skills, supporting his theory that these two methods are superior to all other methods 
in developing straight-copy speed and accuracy.

At a summer workshop at PSU, 1979, Dr. West indicated he had no information concerning a comparison of the effects of paced and progressive practice on straight-copy speed and accuracy development. After having read many of Dr. West's publications and talking with him during the workshop, I became convinced of the soundness of his recommended skillbuilding principles and of the superiority of his recently published textbook.

I was eager to implement these principles and textbook in my classroom and to find out if either of the two skillbuilding methods (paced and progressive practice) were superior in building straight-copy speed and accuracy.

Need for the Study

Information regarding the possible superiority of various skillbuilding procedures is essential as a basis for developing efficient and purposeful classroom activities. This information can and must be obtained through experimental research. According to West ("Design and Conduct of Educational Surveys and Experiments," 1977), "Insofar as what goes on in the classroom is a central determinant of educational outcomes, only experimentation can determine what should happen in the classroom."

The extent to which either paced and/or progressive practice procedures are used in the classroom may be determined by utilization of the results of the study. 
Statement of the Problem

The problem of this study was to determine the effects of progressive practice skillbuilding procedures and paced practice skillbuilding procedures upon the straight-copy typewriting achievement of students enrolled in first-term collegiate typewriting. The procedures were compared on the bases of the dependent variables: 1) straight-copy stroking speed, and 2) straight-copy accuracy.

The following null hypotheses were tested:

1. There will be no significant differences in the straight-copy stroking speeds achieved by students participating in progressive practice skillbuilding procedures and students participating in paced practice skillbuilding procedures.

2. There will be no significant differences in the straight-copy accuracy achieved by students participating in progressive practice skillbuilding procedures and students participating in paced practice skillbuilding procedures.

\section{Purpose of the Study}

The results of this study may be helpful to teachers using the West textbook in determining how much time should be devoted to progressive and/or paced practice procedures in order to provide the most efficient and successful skillbuilding program.

The results of the study may also be helpful to teachers and other researchers who are interested in the effects of external pacing as a training tool. 
Delimitations

The study was delimited to the effects of paced and progressive skillbuilding procedures on the development of straight-copy speed and accuracy. A study of the effects of paced and progressive practice on the development of production typewriting skills was not included.

The accuracy criterion measure was total number of errors. No attempt was made to analyze errors in respect to types and frequencies occurring under the differing modes of practice.

Paced and progressive practice procedures were not compared with any other methods of skillbuilding.

\section{Limitations}

The study is limited to the extent that the information obtained may not apply to high school typing students, nor to college typists at the intermediate and advanced levels.

The two treatment groups met at different times of the day which may have influenced the results of the study.

It was assumed that the amount of outside practice would be equal between the two treatment groups, and therefore, records of outside practice were not required.

Although student work was checked periodically to ensure adherence to the rules of practice, it was not possible to check the work on a daily basis. Therefore, it can only be assumed that students were continuously following the rules of practice. 
Definition of Terms

The following terms are defined as they apply to the study:

Straight-copy typewriting. Word-for-word copying of printed or typed matter, without erasing and without requiring format decisions by the typist.

Straight-copy stroking speed. Average gross words per minute of two five-minute timed writings. Gross words per minute is obtained by dividing the total number of typing strokes by five and dividing this number by the number of minutes the student typed.

Straight-copy accuracy. The sum of the errors made on two five-minute timed writings.

Progressive practice group (PR). The treatment group participating in progressive practice. Under timed conditions, the students pace themselves in an effort to finish a designated amount of material in the time allowed.

Paced practice group (PA). The treatment group participating in paced practice. Under timed conditions, the student's response rate is guided by the external pacing in quarter-minute intervals conducted by the teacher.

syllabic intensity. The average number of speech syllables per dictionary word.

stroke intensity. The average number of typewriter strokes per dictionary word, including interword space. 
Counterbalanced order. A random one-half of the class

takes two five-minute timed writings in $A-B$ order, and the other half takes them in B-A order. This procedure provides empirical evidence for equivalence of copy difficulty uncontaminated by possible "order of administration" or fatigue effects.

\section{Summary}

The development of a usable typewriting skill begins with building straight-copy speed and accuracy. Enrollments in typewriting classes are high. Teachers are in need of research data upon which to base decisions regarding methods and materials for skillbuilding.

This study provides information regarding two

skillbuilding procedures developed and published by Dr. Leonard J. West for use in collegiate typewriting classes. 


\section{CHAPTER II REVIEW OF RELATED LITERATURE}

The author and designer of the methods and materials for paced and progressive practice, Dr. Leonard J. West, stated there have been no experimental studies conducted to compare the effects of these two me thods of practice. No studies were found in a search of the literature.

The basic difference between paced and progressive practice is the external pacing of the response rate feature of the paced practice. Therefore, a search of the literature was undertaken to locate studies in which skillbuilding methods using external pacing were experimentally compared.

In the 1970's, instrumentation in the form of teaching machines, such as the Gregg/Pacesetter and the Automated Touch Typing System, was applied to initial keyboard learning. Although these devices contain a pacing component, studies (Dupras, 1973; Trexler, 1973) dealing with their use were found to be broad comparisons of teacher-directed vs machine-directed learning rather than a study of the effects of external pacing.

Studies completed in the 1950's and 1960's involving the use of mechanical pacing devices provide the only experimentally gathered data regarding the use of external pacing. These studies will be presented in chronological order.

\section{Tachistoscope Studies}

The first two studies involved the use the tachistoscope.

This device is an overnerd projector end flashmeter uhich 
permits one to flash slides of stimulus material on the screen for varying durations.

Winger's study (1951) involved two equated groups of beginning college typists. The experimental group typed using the tachistoscope for ten minutes per day, five days per week, for seven weeks--350 minutes total treatment time. The control group utilizing the same practice schedule typed using regular textbook and supplementary materials. The control group typed from print and dictation. On the 5-minute straight-copy posttest, the experimental group typed 5 wpm faster and made 1.3 fewer errors per 5 minutes--differences were statistically significant.

The study by Palmer (1955) employed two high school classes formed by random sampling. The experimental group typed using the tachistoscope for ten minutes per day, five days per week, for 100 days--total treatment time 500 minutes. The control group typed from regular textbook materials. On the 5 -minute posttest, the experimental group typed $6.3 \mathrm{wpm}$ faster and made 1.8 fewer errors--differences being statistically significant.

The early studies of Winger and Palmer reported the superiority of pacing as a training method. However, the experimental and control groups in these studies typed from different practice materials making it unwise to attribute the differences in terminal proficiency solely to the effects of the pacing variable. 
Skillbuilder Controlled Reader

A study by Kline (1962) using the Skillbuilder Controlled Reader is similar to that of Winger and Palmer in that the control groups typed regular textbook materials while the experimental groups were externally paced. The Skillbuilder Controlled Reader is a $35 \mathrm{~mm}$ filmstrip projector with display rates ranging from 12 to 108 wpm in 6 wpm steps. The device presents material in a left to right motion by means of a moving slot.

The study employed equated beginning high school typing classes who typed for ten minutes per day, five days per week, for 70 days--total treatment time 700 minutes. The procedures for the control groups were entirely up to the instructor. One experimental class discontinued use of the Reader at the end of the first semester. At the end of the first semester, the experimental groups typed 6.0 wpm faster and made 2.1 fewer errors per five minutes--differences being statistically significant. No statistically significant difference was found between the experimental group which had continued paced work during the second semester and the experimental group which had discontinued paced work at the end of the first semester.

The results of the Kline study are suspect because different materials were used and because procedures for the

control groups were left entirely up to the instructor permitting the inclusion of many uncontrolled variables. 
Johnson (1962) in a study to determine the effects of the Skillbuilder Controlled Reader on skill development in beginning and intermediate college typewriting classes, divided each section of the experimental group (paced) into three groups according to initial gross stroking ability. No information was presented regarding the procedures used in the control groups or total treatment time. On a l-minute straight-copy timed writing, a difference of .28 gwpm was found between the experimental groups and the control groups in the beginning classes--difference was not statistically significant. On a 5minute timed writing, a difference of $4.49 \mathrm{gwpm}$ was found in favor of the experimental group in the intermediate classes-this was significant at better than the 1 percent level. Johnson also concluded that "better" students are more likely to benefit from machine training.

Perkins (1963) designed an experiment to contrast the pacing function performed by a Skillbuilder Controlled Reader with that of a pacing function performed by a teacher. The experimental group (machine) and the control group (teacher) used the same textbooks, materials, typewriters and classroom facilities. The experiment was conducted for 10 minutes per day, 3 days per week for seven weeks--total treatment time 210 minutes. Ability grouping was used in the experimental classes but not in the control classes. Students in the control classes were instructed to keep their eyes on words and phrases of the 
drill sheet and to respond as each unit was dictated. The interval between dictated units was about one second. The experimental groups typed 4.3 wpm faster and made 2.0 fewer errors per five minutes on the pretest--not statistically significant; on the posttest, the experimental groups typed 5.1 wpm faster and made .7 fewer errors per five minutes--not statistically significant.

Perkins concluded there is no reason to expect any differences between a teacher and a mechanical device when both perform the same function.

The studies previously discussed relate to the use of group pacing devices. Two studies were conducted in 1965 involving the use of an individualized pacing device--the strong Pacer.

\section{Strong Pacer}

This device indicates at periodic intervals at what point in the copy the typist aiming at a certain rate should be rather than removing the copy from view. A pointer at the left of the copy drops down to each new line (with an audible click) to indicate that the preceeding line should have been completed.

Tranquill (1965) compared a Strong Pacer group against a drill group (using the Strong Pacer materials, but not the device) against a group conventionally trained with regular textbook materials. Students were assigned to groups on the basis of straight-copy speed. 
The three groups of second and fourth semester high school students practiced for ten minutes per day, five days per week for fifteen weeks- -750 minutes total treatment time. On straight-copy posttests, the Pacer group was about two wpm faster and $1 / 2$ to 1 point higher in percent of accuracy than the other two groups--difference being statistically significant. The procedural error of "perfect copy" practice may have watered down the effects of the practice.

Tranquill also concluded that gains in speed achieved through individualized pacing are not subject to decline and that students of low typewriting ability appear to benefit from individualized pacing to a greater degree than average or higher leve 1 students.

Another study of the use of the Strong Pacer was conducted by Bryson (1965) in which the effects of the device were compared with the effects of teacher pacing. Intact advanced and intermediate college typewriting classes were used. The experimental groups (using 12 strong Pacers) and the control groups (following generally accepted pacing drills) practiced for ten minutes per day, three days per week for twenty weeks-200 minutes total treatment time. One experimental group used the Strong Pacer materials but not the device.

Bryson found there was no difference in the results from the Pacer or non-Pacer methods in advanced or intermediate 
typewriting, the use of Pacer materials or the retention of skills.

\section{Other Mechanical Devices}

In a study by McAnally (1966), the experimental groups were paced using the SRA Mark III and the control groups typed the same exercises without the use of the Pacer. Intermediate and advanced college students participated in the fourteen week study.

The differences in gross words a minute or correct words a minute between the experimental and control groups was not statistically significant at the end of fourteen weeks. Mean net words per minute was higher for the experimental group-difference was significant at the five percent level. The accuracy rate was better for the experimental group--difference was significant at the one percent level. McAnally also found that the use of mechanical pacers was more beneficial to students enrolled in intermediate classes than to students enrolled in advanced classes.

Shell (1965) investigated the use of the diatype, an analyzer/pacer. A motor pulls a sheet of regular typing paper through the typewriter at a constant rate in one minute, resulting in a graphic picture of the student's typing. The picture can then be analyzed to determine techniques which require attention. Following the diagnosis, the student 
practices remedial drills using the machine as a pacer.

Shell found the diatype to be effective in developing speed, but its effectiveness in developing accuracy was not established. Due to the dual function of this machine, the effects cannot be attributed solely to the pacing variable.

Rhodes (1972) used an external pacing device of his own design and found the paced group increasing 1.9 wpm more than did the group who used regular textbook drills. Rhodes randomly selected eight students, two from each class, to form the experimental group. The remainder of the beginning high school students (92) constituted the control group. Students in the experimental group used the pacing device during the initial five to ten minutes of the class period from the ninth week of intruction through the thirty-fifth week.

Rhodes described his study as a pilot effort and stated that the optimum devices and methods for pacing had yet to be de termined.

\section{$\underline{\text { Summary }}$}

In the studies cited involving mechanical pacing devices, pacing appears to be superior to untimed practice. There appears to be no difference between the effects of teacher pacing and machine pacing. However, the studies completed to date have not provided information as to the value of external pacing in comparison with other rate-forcing techniques, which is the purpose of this study. 


\section{CHAPTER 3 METHODS AND PROCEDURES}

This section describes the methods and procedures used in the study. The major areas considered are: 1) selection of the subjects, 2) research technique, 3) description of the treatments--paced and progressive practice, 4) duration of the treatments, 5) description of the materials, 6) testing, and 7) treatment of the data.

Selection of the Subjects

The study subjects were from two intact classes of beginning college typewriting at Portland State University. The classes were formed through regular university registration procedures including computer-assisted preregistration and a follow-up add-drop system. The researcher did not assign students to the classes. Classes were filled on a first-come-first-served basis.

Both classes met during Fall term, 1979, on a Monday, Wednesday, Friday sequence: Section 1 at 9 AM and Section 3 at 12 PM.

Students in these classes who participated in at least 66 of the 114 minutes of treatment time constitute the sample for the study. Sample size is fifty-two--twenty-six per treatment group. 
of the twenty-six subjects in the 9 AM class (Paced group), there were 9 males and 17 females; 5 English as a second language students; 8 "true" beginners, 5 self-taught typists, and 13 who had had some high school typewriting training.

of the twenty six subjects in the 12 PM class (Progressive group), there were 12 males and 14 females; 9 English as a seconld language students; 11 "true" beginners, 7 self-taught typists, and 8 who had had some high school typewriting training.

\section{Research Technique}

The effects of the two treatments were compared experimentally. Two intact groups were used necessitating a non-equivalent treatment group design. Following Campell and Stanley (1963), the research design--employing a notation later used by Hillestad (1977)--is depicted as follows (dotted line indicates intact groups):

$$
\frac{{ }_{1} a^{\top} A^{0} 2 a}{{ }^{0} b_{b}{ }^{\top}{ }^{0} 2 b}-
$$

A pretest was administered $\left(0_{1}\right)$, the experimental procedures were conducted $(T)$, and a posttest was administered $\left(\mathrm{O}_{2}\right)$. Two interim tests were administered to determine weekly effects of the treatments.

Assignment of the treatments. The assignment of treatments to the treatment goups was made by flipping a coin. Paced 
practice was conducted for the 9 AM class and progressive practice for the 12 PM class.

Teaching. Both treatment groups were taught by the researcher. Prior to the study, the researcher had no opinion regarding the superiority of either of the two treatments. Detailed lesson plans were followed in order to ensure uniform class activities.

Attendance. Students were made aware that they were participating in a research study. They were informed that two highly recommended skillbuilding practice methods were being compared. They were asked to make every effort to attend class on a regular basis. Rigorous attendance-taking procedures were followed.

Privacy. Students were assured that names would not be used in the study and that any individual scores used would be identified by using Student \#1, Student \#2, etc. Students were also informed that their timed writings might be proofread and scored by individuals other than the instructor.

Students were requested to register any objections to their inclusion in the study to the instructor. No objections were raised.

Monitoring the practice. Following the third and fifth practice sessions, all student typescripts and practice record forms were collected and analyzed to evaluate adherence to the rules of practice. Reminders were issued to students where ne ce s sary. 
No effort was made to limit outside-of-class practice. Students in each treatment group were given identical homework assignments and were asked not to use the paced or progressive materials outside of class.

Facilities and Observers. Both classes met in the same room, one at 9, the other at 12--with shades drawn for the latter class to keep the room cooler.

Students from a typewriting methods class were regular observers on Wednesdays. The 12 PM class had four observers-the 9 AM class had one. These students presented several lessons during the course of the study, but were not involved in administering the paced or progressive practice.

Description of the Treatments

Progressive and paced practice are structurally and procedurally alike. Both are rate-forcing skillbuilding methods in which the student attempts to achieve a speed or accuracy goal under timed conditions. Progressive practice derives its name from the progression to a new speed or accuracy goal made by the student upon achievement of an earlier goal. Paced practice adds external pacing of the response rate to the features of progressive practice.

Both modes of practice allow the student to practice according to individual needs. Individualized practice schedules permit the student to begin speed or accuracy practice 
a few words per minute above a pretest speed. Substantial gains in speed (4-6 wpm) are developed before the student switches to accuracy practice. Errors standards for accuracy practice are based on research data showing two errors per minute as reasonable.

Practice materials for both modes of practice are located in the text on consecutive pages facilitating convenient administration. New copy is provided for each new speed goal.

The basic difference between paced and progressive practice is the external quarter-minute interval pacing feature of the paced practice. Students participating in progressive practice are provided with an amount of material that must be finished in the time allowed (1-minute timings initially, followed by two-minute timings). Students participating in paced practice are required to finish a certain amount of material in the time allowed but are aided in this effort by quarter-minute interval pacing conducted by the teacher.

Timings for paced practice are two to five minutes in duration and are designed to maximize transfer of performance to the typical five-minute timings of employment tests.

Conducting the practice. The procedures for paced and progressive practice were those specified in the textbook, Modern College Typewriting--A Basic Course, and its accompanying instructor's manual, further supported and illustrated by 1 ive demonstration by Dr. West in a PSU typing methods class in 
June, 1979, and by an interchange of correspondence with him before and during the conduct of the experiment.

Those procedures, as we 11 as the rationale underlying the two modes of practice, are also expressed in a monograph by West (1979), and can most conveniently be stated by direct quotation from the monograph (See Appendix 1).

Pretest scores of 0 ctober 12 were used to determine a practice starting point for each student. All students began with speed goals. Practice record forms were filled out by the researcher prior to the first practice session on 0ctober 15 in order to ensure appropriate initial practice goals. A demonstration and explanation of the practice procedures was conducted on october 12 and students were invited to ask questions. All nine practice sessions were conducted at the beginning of the class periods. A stopwatch was used for all timed work.

\section{Procedures for progressive practice. At the first} practice session on 0 ctober 15 , students were instructed to insert paper in the typewriter, set margins of 12 and 90 , set typewriter on single spacing, and to clear all tab stops. They were asked to place practice record forms to the left of the machine and textbooks to the right. They were then instructed to check the practice schedule to determine the goal and to locate that piece of material in the textbook.

Once materials and machines were ready, the progressive 
practice timing was initiated via a countdown (ready, 3, 2, 1 ). Students began typing on 1 and continued until they heard the call to "stop." At this point they double spaced and began checking their work. A rest period was provided for this checking. During the rest period, students were asked to indicate a goal reached by "lining out" that goal on the ir practice schedule. Following the rest period, the next timing was begun via countdown--and so on.

During the first four practice sessions, twelve one-minute timings were administered each session. New practice record forms, constructed by the researcher, were distributed on October 24 when timing durations were increased to two minutes. The starting points for these schedules was determined by interim testing administered october 22.

Two errors per minute was used as the accuracy standard during accuracy practice; two errors allowed on a one-minute timing and four errors allowed on a two-minute timing.

Procedures for paced practice. At the first practice session on October 15, students were instructed to insert paper in the typewriter, set margins of 12 and 90 , set machine on double spacing, and set a tab for a 5-space paragraph indention. They were asked to place practice record forms to the left of the machine and textbooks to the right. They were then asked to check the practice record form to determine the goal and to locate that piece of material in the textbook. 
Once materials and machines were ready, the first timing was begun via a countdown (ready, $3,2,1$ ). Students began typing|on 1 and continued until they heard the call to "stop." At this point they double spaced and began checking their work. They were informed of the length of the timing and were instructed to check the copy to determine if the speed goal had been met and to check the error allowance chart to determine the number of errors allowed for that length of timing if working on an accuracy goal. Rest periods were provided for checking. During the paced timings, the teacher called out 1/4minute intervals. Internal marking of the textbook copy served as a guide, and students were to be within five strokes either side of the marked interval in the copy when the teacher announced the corresponding time interval or to adjust the ir stroking rates accordingly. When stop was called, the student was to be within five strokes either side of the marked interval corresponding to that timing length. Timing lengths were not announced in advance.

\section{Duration of the Treatments}

The study was conducted during a period beginning october 12, 1979, and ending November 5, 1979. The treatment groups met on a MWF sequence--each for fifty minutes per day. The study began at the conclusion of alphabetic keyboard presentation which had started September 26, 1979. During the treatment period, number-symbol keys and centering were taught in addition to the skillbuilding activities. 
Total treatment time for each group was 114 minutes. Only actual typing time excluding rest periods is included as treatment time. The study began with a pretest on 0ctober 12 , 1979. Treatments began 0ctober 15, 1979. There were nine practice sessions; the first six sessions involved twe lve minutes of practice time each session, and the last three sessions involved fourteen minutes of practice time each session. The posttest was administered November 5, 1979. Interim tests were administered 0ctober 22 (after 36 minutes of practice) and on 0ctober 29 (after 72 minutes of practice).

Table 3-1:

STUDY TIMETABLE

\begin{tabular}{ll}
\multicolumn{1}{c}{ Date } & \multicolumn{1}{c}{ Activity } \\
October 12, F & Pretesting \\
October 15, M & Practice--12 minutes \\
October 17, W & Practice--12 minutes \\
October 19, F & Practice--12 minutes \\
October 22, M & Interim Testing \\
October 24, W & Practice--12 minutes \\
October 26, F & Practice--12 minutes \\
October 29, M & Practice--12 minutes \\
October 31, W & Interim Testing \\
November 2, F & Practice--14 minutes \\
November 5, M & Practice--14 minutes
\end{tabular}


The durations of progressive practice timings for each of the nine practice sessions are illustrated in Table 3-2.

Table 3-2:

DURATIONS OF TIMINGS FOR PROGRESSIVE PRACTICE

$$
\begin{aligned}
& \text { October } 12,17,19,22 \\
& \text { Twe I ve } \\
& \text { 1' Timings } \\
& \text { October } 24,26 \\
& \text { Six } \\
& \text { 2' Timings } \\
& \text { October } 29,31 \text {, November } 2 \\
& \text { Se ven } \\
& \text { 2' Timings }
\end{aligned}
$$

Timing durations for paced practice were of various lengths. Durations of timings for each practice session are illustrated in Table 3-3 (in minutes).

Table 3-3:

$$
\text { DURATIONS OF TIMINGS FOR PACED PRACTICE }
$$

October 15 0ctober 17 October 19 0ctober 22 October 24

$\begin{array}{ll}2 & \\ 1 & 1 / 2 \\ 2 & 1 / 2 \\ 1 & 3 / 4 \\ 2 & 1 / 4 \\ 2 & \end{array}$

$$
\begin{aligned}
& 23 / 4 \\
& 31 / 4 \\
& 21 / 2 \\
& 31 / 2 \\
& 31 / 2 \\
& 21 / 2 \\
& 31 / 4 \\
& 23 / 4 \\
& 41 / 4 \\
& 33 / 4
\end{aligned}
$$$$
33 / 4
$$$$
4
$$$$
41 / 4
$$

October 26

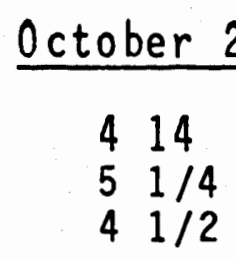

$33 / 4$

$41 / 4$

October $31 \quad$ November 2

$51 / 4$

$41 / 2$

$41 / 4$

$41 / 2$

$41 / 4$

$51 / 4$ 
Description of Materials

The textbook, Modern College Typewriting--A Basic Course, by Dr. Leonard J. West was the text used by the two classes involved in the study. The progressive practice and paced practice skillbuilding materials are located in the text. Dr. West provides carefully constructed new copy for each new goal using ordinary prose.

Progressive practice materials. Sentences and paragraphs are progressively graduated in length with new material provided for one-minute goals of 4-67 wpm and two-minute goals of 5-66 wpm (in one-minute intervals). The se materials are located on Pgs. 127-134 of the text and a sample is provided in Appendix 2. Paced practice materials. The se materials consist of five minutes of copy at each even-numbered speed from 10-74 wpm. Each piece of copy is marked in 1/4-minute intervals. These materials are located on Pgs. 139-155 of the text and a sample is provided in Appendix 2.

Practice record forms. These forms were duplicated from the one provided in the instructor's manual accompanying the text. Examples of completed practice forms for students participating in paced and progressive practice are located in Appendix 3.

Error allowance chart--paced practice. An error allowance chart based on two errors per minute was distributed to the paced practice group due to the varying lengths of timings (Appendix 4). 


\section{Testing}

Straight-copy speed (gross words per minute to the nearest tenth) and straight-copy accuracy (number of errors) were used as criterion measures.

Pretest and posttest scores were obtained by the administration of a pair of five-minute timed writings. Materials for the timed writings were duplicated from the textbook used in the class and Dr. West's text for intermediate college typewriting. Copies of these timings are located in Appendix 5 .

The testing procedures followed were those developed by the researcher for use by PSU typewriting instructors and are located in Appendix 6. The only deviation from the se procedures as written was the use of several timings duplicated from the textbook in use by the classes. The testing procedures were designed to ensure maximum reliability and validity in the me asurement of straight-copy proficiency.

Treatment of the Data

Analysis of covariance was performed to test the two null hypotheses using pretest measures as covariates. Statistical significance at the .05 level was necessary to reject the null hypotheses.

The software used for the analysis of covariance was a program in the Statistical Package for the Social Sciences adapted for use in this study by Ms. Karen King, research 
assistant at the Institute of Aging. This program also provided measures of central tendency and distribution.

The hardware utilized was PSU's Honeywell computer.

\section{Summary}

Paced and progressive practice procedures were compared experimentally involving two groups in a pretest, treatment, post test research design.

After 114 minutes of treatment time an analysis of covariance was performed on the criterion variable scores to determine any differences in straight-copy stroking skills resulting from the differing methods of practice. 
CHAPTER 4 FINDINGS, CONCLUSIONS AND RECOMMENDATIONS

The problem of the study was to compare the effects of paced practice and progressive practice on the development of straight-copy stroking skills in beginning collegiate typewriting. The following null hypotheses were tested:

1. There will be no significant differences in the straight-copy stroking speeds achieved by students participating in progressive practice skillbuilding procedures and students participating in paced practice skillbuilding procedures.

2. There will be no significant differences in the straight-copy accuracy achieved by students participating in progressive practice skillbuilding procedures and students participating in paced practice skillbuilding procedures.

\section{FINDINGS}

Utilizing the "Measurement of Straight-Copy Proficiency Procedures" developed by the researcher (Appendix 6), the paced and progressive groups were administered a pretest and posttest each consisting of two 5-minute timed writings. The speed scores were obtained by dividing the total number of words typed on the pair of timings by 10 and are reported in the following tables as GWPM--gross words per minute. The error scores were obtained by summing the number of errors made on the pair of 
timings and are reported in the following tables as number of errors (\#E).

The findings of the study will be presented in two sections: 1) a description of the data including raw scores and measures of central tendency and distribution, and 2) the analysis of covariance performed to determine statistical significance of the results of the study.

Description of the Data

Fifty-two students were included in the study--twenty-six students in the paced group and twenty-six students in the progressive group. A student who had participated in at least 66 minutes of the 114 minutes of treatment time and was present for the pretest and the posttest was included in the data analysis.

Raw Scores. The following two tables represent the individual speed and accuracy scores on the pretest and the posttest for the fifty-two students included in the study. The tables also show the minutes of practice time completed by each of the fifty-two students.

Table 4-1 (Pg. 30) provides this information for the twe nty-six students participating in paced practice procedures.

Table 4-2 (Pg. 31) provides this information for the twenty-six students participating in progressive practice procedures. 
Table 4-1:

INDIVIDUAL PRE- AND POSTTEST SPEED AND ACCURACY SCORES AND MINUTES OF PRACTICE--PACED PRACTICE GROUP (Speed = Gross Words per Minute; Accuracy = Number of Errors)

\section{Pretest}

$\underline{\text { Student \# }}$

1

2

3

4

5

6

7

8

9

11

12

13

14

15

16

17

18

19

20

21

22

23

24

25

26
GWPM \#E

$16.0 \quad 18$

32.69

$15.8 \quad 17$

13.5

13.8

11.0

23. 5

9.7

16.7

26.4

28.5

30.6

40.6

13. 5

$23.9 \quad 25$

17.013

26. $0 \quad 54$

$21.5 \quad 17$

22. $7 \quad 41$

$19.1 \quad 13$

$25.0 \quad 25$

$16.7 \quad 13$

30.130

$39.3 \quad 24$

$28.9 \quad 58$
$47.5 \quad 11$

\section{Posttest}

GWPM \#E

$27.4 \quad 46$

$39.8 \quad 41$

23. $8 \quad 36$

$24.2 \quad 18$

$25.5 \quad 29$

12.147

$32.5 \quad 46$

$14.5 \quad 14$

Minutes

Practiced

114

114

114

114

114

114

114

114

$16.9 \cdot 40$

$30.7 \quad 49$

$33.3 \quad 64$

34.5

42.5

24.7

20

37

$26.4 \quad 43$

52.6

22.3

15

27

61

30.4

28.4

28.2

55

38

90

$22.5 \quad 27$

$27.7 \quad 54$

88

88

$20.4 \quad 37$

$33.6 \quad 35$

86

86

$43.5 \quad 42$

76

$31.4 \quad 23$

66 
Table 4-2:

INDIVIDUAL PRE - AND POSTTEST SPEED AND ACCURACY SCORES AND MINUTES OF PRACTICE--PROGRESSIVE PRACTICE GROUP (Speed = Gross Words per Minute; Accuracy $=$ Number of Errors)

Pretest

Student \#

GWPM \#E

20.823

25.7

16.4

9.2

17.9

29.3

35.0

8

20

10

34

20

$19.0 \quad 18$

14.9

27.8

18.4

28

37

6

$21.1 \quad 22$

$33.9 \quad 39$

$16.6 \quad 28$

13.9

33.2

11.0

18.7

13

64

17

18

19

20

21

22

23

24

25

26

$12.9 \quad 25$

16.25

$16.9 \quad 18$

$27.5 \quad 40$

$18.7 \quad 15$

14.352

$30.4 \quad 24$

$27.0 \quad 8$

\section{Posttest}

GWPM \#E

34.5

29. 1

22.3

12.3

18.9

34.8

40.2

63

13

43

11

23

49

44

20.4

22.3

33.0

22.4

15

41

27

13

23.6

36.4

20.8

20.1

41.7

14.2

19.3

42

41

24

42

78

39

35

15.8

20.0

24.1

29.5

27

22

45

51

Minutes

Practiced

114

114

114

114

114

114

114

102

102

102

102

100

100

100

100

100

100

100

88

88

88

88

$22.8 \quad 46$

78

$20.6 \quad 45$

76

$39.6 \quad 40$

$33.6 \quad 26$

74

74 
The average (mean) practice time of students in the paced group was 99.77 minutes (standard deviation of 12.97) compared 40 98. 46 minutes (standard deviation of 13.14) for students in the progressive group.

Descriptive statistics. The following four tables (4-3, 4-4, 4-5, and 4-6) show the measures of central tendency and measures of dispersion for pre- and posttest speed and accuracy scores by group.

Table 4-3:

MEASURES OF CENTRAL TENDENCY AND DISTRIBUTION OF PRE - AND POSTTEST SPEED SCORES--PACED GROUP

(Speed Scores in Gross Words per Minute)

Me asure

Me an

Standard Deviation

Mode

Median

Range
Pretest

23.458

9.552

13.500

22.800

$9.7-47.5$
Posttest

28.838

9.065

12.100

27.800

$12.1-52.6$

Table 4-4:

MEASURES OF CENTRAL TENDENCY AND DISTRIBUTION OF PRE - AND POSTTEST SPEED SCORES--PROGRESSIVE GROUP (Speed Scores in Gross Words per Minute)

\section{Measure}

Me an

Standard Deviation

Mode

Median

Range
Pretest

21.027

7.386

18.700

18.700

$9.2-35.0$
Posttest

25.858

8. 399

22. 300

22. 450

$12.3-41.7$ 
The increase in speed by the paced group as represented by the change in mean GWPM between the pretest and the posttest is +5.380 compared to +4.831 for the progressive group. The paced group's gain in speed was . 549 GWPM greater than the gain in speed by the progressive group.

Both the pretest standard deviation and the posttest standard deviation are larger for the paced group indicating a greater degree of score variability in the paced group.

An examination of the changes in standard deviation (from pretest to posttest) within each group reveals a narrowing in the distribution of scores for the paced group and a widening of the distribution of scores for the progressive group.

Table 4-5:

MEASURES OF CENTRAL TENDENCY AND DISTRIBUTION OF

PRE - AND POSTTEST ACCURACY SCORES--PACED GROUP (Accuracy Scores in Number of Errors)

Me asure

Me an

Standard Deviation

Mode

Median

Range
Pretest

23.308

15.260

13.000

17.500

3-58
Posttest

36.654

14. 588

27.000

37.500

$9-64$ 
Table 4-6:

MEASURES OF CENTRAL TENDENCY AND DISTRIBUTION OF PRE - AND POSTTEST ACCURACY SCORES--PROGRESSIVE GROUP (Accuracy Scores in Number of Errors)

Me asure

Me an

Standard Deviation

Mode

Median

Range
Pretest

25.538

14.787

8.000

23.000

$5-64$
Posttest

36.346

15.877

13.000

40.500

$11-78$

The number of errors was higher on the posttest than on the pretest for both groups. The increase in the mean number of errors for the paced group is +13.346 compared to +10.808 for the progressive group. The paced group's increase in mean number of errors is 2.538 greater than the increase in number of errors by the progressive group.

In order to determine the statistical significance of the preceding differences in measures of central tendency and distribution, an analys is of covariance was performed.

\section{Analysis of Covariance}

Analysis of covariance (ANCOVA) was performed on the posttest scores for each dependent variable. The covariate used in analyzing the speed variable was pretest speed. The covariate used in analyzing the accuracy variable was pretest accuracy. 
ANCOVA--Speed. Results of the ANCOVA to determine the significance of the posttest differences in speed are an $F$ value of 0.565 . The level of significance of this value, with 1 and 49 degrees of freedom, is .465. A.05 level of significance is necessary to reject the null hypothesis. Therefore, the null hypothesis, there will be no significant differences in the straight-copy stroking speeds achieved by students participating in progressive practice skillbuilding procedures and students participating in paced practice skillbuilding procedures, is not rejected.

ANCOVA--Accuracy. Results of the ANCOVA to determine the significance of the differences in posttest accuracy are an $F$ value of 0.169 . The level of significance of this value, with 1 and 49 degrees of freedom, is .682 . A.05 level of significance is necessary to reject the null hypothesis. Therefore, the null hypothesis, there will be no significant differences in the straight-copy accuracy achieved by students participating in progressive practice skillbuilding procedures and students participating in paced practice skillbuilding procedures, is not rejected.

CONCLUSIONS

The utilization of either paced or progressive practice skillbuilding methods in a skillbuilding program is likely to produce similar results in regard to straight-copy speed and

\section{agsuracy,}


The addition of external pacing in quarter-minute intervals to timed skillbuilding practice did not result in superior speed or accuracy gains.

Paced and progressive practice procedures produced an increase in the number of straight-copy errors rather than an improvement of accuracy.

\section{RECOMMENDATIONS}

1. A skillbuilding program in which students participate in both paced and progressive practice procedures may produce results different from those found in this study. Possibly, there is a combination of paced and progressive practice that would aid in developing speed and accuracy scores superior to the ones obtained in this study. A future study to determine the best combination of practice is recommended.

2. Recognition is given to the increase in number of errors by both groups in the study. This increase may be a result of the speed-forcing nature of both types of practice or it may be the result of insufficient monitoring of the students' accuracy goal achievement during the practice sessions. A future study in which all accuracy goals crossed off by students are verified by the researcher is recommended in order to ensure strict adherence to the rules of accuracy practice.

3. Any possible differences in the effects of paced and progressive practice may not be exhibited after 114 minutes of 
treatment time. A study of the effects of the different practice methods after a longer period of treatment time is recommended.

4. A sample size of twenty-six per treatment group requires large differences to be statistically significant. A future study with a larger sample size is recommended. 
In the two types of skillbuilding programs described and illustrated next, there is complete individualization of practice under procedures in accord with reliable present day knowledge about how stroking skills are most efficiently and effectively acquired.

As shown by the portions of student-maintained practice forms accompanying the sample materials (Appendix 3 ), a straight-copy test timing precedes first use of the materials, and each student begins with speed practice at a speed just above his or her next gross wpm test speed (in Progressive practice, 1 wpm above, in Paced practice, at the next higher even numbered speed).

Thereafter, practice is entirely according to one's practice schedule, without further test timings; each time skillbuilding practice is done, students continue where they left off the time before. As a success is achieved, the student lines out the corresponding record entry. The sample Progressive practice record for Alice (Appendix 3 ) shows that at the next practice session she should begin with $S$ (Speed) practice at 19 wpm, whereas Bob should begin with A (Accuracy) practice at 23 wpm. The sample Paced practice record (Appendix 3 ) is interpreted the same way.

Progressive Practice. As used in Modern College Typewriting, the recommended practice sequence, evident in the sample practice record is "up 5, down 2." Work for a 5-wpm gain in gross speed (1 wpm at a time); then drop back 2 wpm for accuracy practice. When you can type with reasonable accuracy at your previous best speed, return to speed practice for another "up 5, down 2" cycle A success at any speed timing requires finishing the item in the time al lowed ( 1 minute or 2 minutes), regardless of errors. Success at accuracy practice adds to the speed requirement: "with no more than 2 errors per minute" (2 errors in a 1 -minute timing, 4 in a 2-minute timing).

Paced Practice. The Paced practice materials provided in Modern College Typewriting, consist of precisely five minutes worth of copy at each even numbered speed from 10 through 74 wpmb As illustrated, each piece of copy is marked internally in 1/4minute intervals. With Progressive practice intended for timings of up to two minutes, Paced practice is deșigned for longer

practice timings--in accord with the need to make practice durations gradually reach employment test durations. Accordingly, the earliest paced timings should vary between $2-3$ minutes; next, between 3-4 minutes; finally, from, 4-5 minutes. The durations of a typical 3-timing series on some occasion might be, for example, $33 / 4$ minutes, $31 / 4$ minutes, 4 minutes. Either using the timing tapes available from the publisher or by your 
voice and stopwatch, call out, very loudly, the successive 1/4minute intervals $(1 / 4,1 / 2,3 / 4,1$ minute, $1 / 4,1 / 2,3 / 4,2$ minutes, and so on). Students type continuousiy, attempting to adjust their stroking rates so as to just reach the marked point in the copy as each 1/4-minute interval is announced--speeding up when behind, slowing down when ahead of the desired point in the copy. In that way, students learn to adjust their rates to the desired one.

Success in speed practice requires finishing within five strokes on either side of the exact point in the copy when "stop" is called. For example, in a $31 / 2-m i n u t e$ timing a student aiming at 20 wpm (See Line 2 of the second paragraph of the $20 \mathrm{wpm}$ copy--Appendix 2) should finish between the $t$ of type and the space between short and words. Accuracy practice has the same speed requirement plus no more than 2 epm (e.g., 7 errors in a $31 / 2$-minute timing). Timing duration should never be announced in advance; otherwise, students can race to the marked point in the copy and stop, thus defeating the entire purpose of the practice. Finally, as with Progressive practice, a 5-minute test timing precedes the first practice (to determine each student's starting speed), and students follow their individual practice records thereafter. As illustrated (Appendix 3) Al ice's test speed of 18 gross wpm mandates starting Paced practice at 20 wpm; and her practice record shows that her next practice should be for speed at $28 \mathrm{wpm}$ (following successes at the lined-out speeds shown in her record). Here and in Progressive Practice you move ahead if you succeed, if not, you repeat the same copy toward the same goal until you do succeed.

Quoted directly from Monograph \#1, "Principles and Procedures for Teaching Typewriting, "with permission of Dr I Heste 
10 wpm (Sy 1.30)

At the dawn of mankind's 'ifife on earth, there was 'no one to explain things. Many a question had no quick ansiver." Today, there are answers/to many things that puzzle people, young or old." We stand on the shouldër $\$$ of our ancestors through the ages.

\section{2 wpm (Sy 1.31)}

To have an open mind is to have something of real worth as we go through life. It means that we are willing to modify our opinions if there are good reasons for changing them. It means that we are willing to ${ }^{1 / 2}$ consider new ideas, however strange they may ${ }^{1 / 4}$ at first seem to be. Life never stands still.

\section{0 wpm (Sy 1.35)}

In the beginning stages of learning to type, one thinks and types letter by letter. Indeed, sharply' pronouncing each letter ${ }^{1 / 4}$ to yourself as you strike its key not only helps you to learn the keyboard, but als $\Phi$ develops good s/stroking techniques.

Latêr on, you find you no lon̈ger have to name each letter as you type it. You"come to be able to type short words and parts of İonger words without having to think of each separäte letter. When that happens, you are well on the road to prenuine skills.

An exceptionally popular item of women's jewelry is the pearl necklace. The young womau" who shops for har first parl necklace will discover that there are natural pearls, cultured pearls, and artificial pearls. She may wonder what the differences are among the various "types 
Be sure to pay.

She shall not go.

They held it for us.

It should be paid for.

Rush the form to the men.

$I$ have seen all of the men.

When both men come, we may go.

Give the money to the other man.

He can keep that much cash on hand.

They will remain together a long time.

He says that they have to go away today.

Leave your full name with the chief clerk.

Take the time to work it out in the best way.

This makes the third time we have had to return.

It is not easy for us to know the right way to go.

I shall send you the letter as soon as I have the time.

If there is one thing I want to do well, it is to typewrite.

We shall take the usual discount on the order received last week.

19 The head of the firm has just returned from a long tour of inspection.

20 I am sorry to hear that he will be unable to come to the meeting next week.

There is nothing we can do to help you unless you submit your claims in writing.

We hope to hear from you soon about the order we placed with you for five dozen pens.

Each time you repeat one of these exercises you should get closer to the goal of completing the sentence in the time allowed.

If you do not rush too fast the first time you try each of these sentences, you will sooner be able to complete it with real ease.

71. There are several different styles used in listing references at the end of a report. All of them contain three sections showing, in order: author, title, and publication information. Differt ences among the various styles are found in such matters as punctuation within and between sections, capitalization, and quotation marks.

Corrections can be made by typewriting eraser. with specially coated correction tape or strips, or by various white correction fluids painted over the error with a small brush. If you are typing only an original or if copies are to be made by machine, coated correction paper i\$ fastest, but fluids do the best and most permanent job. 


\section{Paced.Practice Record}

\begin{tabular}{|c|c|c|c|}
\hline \multicolumn{2}{|c|}{ Alice } & \multicolumn{2}{|c|}{ Bob } \\
\hline \multicolumn{2}{|c|}{$\begin{array}{l}5^{\prime} \text { wpm }=18 \\
\text { Start at }=20\end{array}$} & \multicolumn{2}{|c|}{$\begin{array}{l}5^{\prime} \text { wpm }=-27 \\
\text { Start at } \\
28\end{array}$} \\
\hline \multicolumn{2}{|c|}{ Schedule } & \multicolumn{2}{|c|}{ Schedule } \\
\hline s & A & $\mathrm{s}$ & A \\
\hline 20 & & 28 & \\
\hline $2 z$ & & 30 & \\
\hline 24 & & 32 & \\
\hline & -22 & & -30 \\
\hline & 24 & & 32 \\
\hline 26 & & 34 & \\
\hline 28 & & 36 & \\
\hline 30 & & 38 & \\
\hline & 28 & & 36 \\
\hline & 30 & & 38 \\
\hline 32 & & 40 & \\
\hline 34 & & 42 & \\
\hline & 32 & & 40 \\
\hline & 34 & & 42 \\
\hline 36 & & 44 & \\
\hline$E$ & & $-E$ & $c$. \\
\hline
\end{tabular}

\section{Progressive Practice Record}

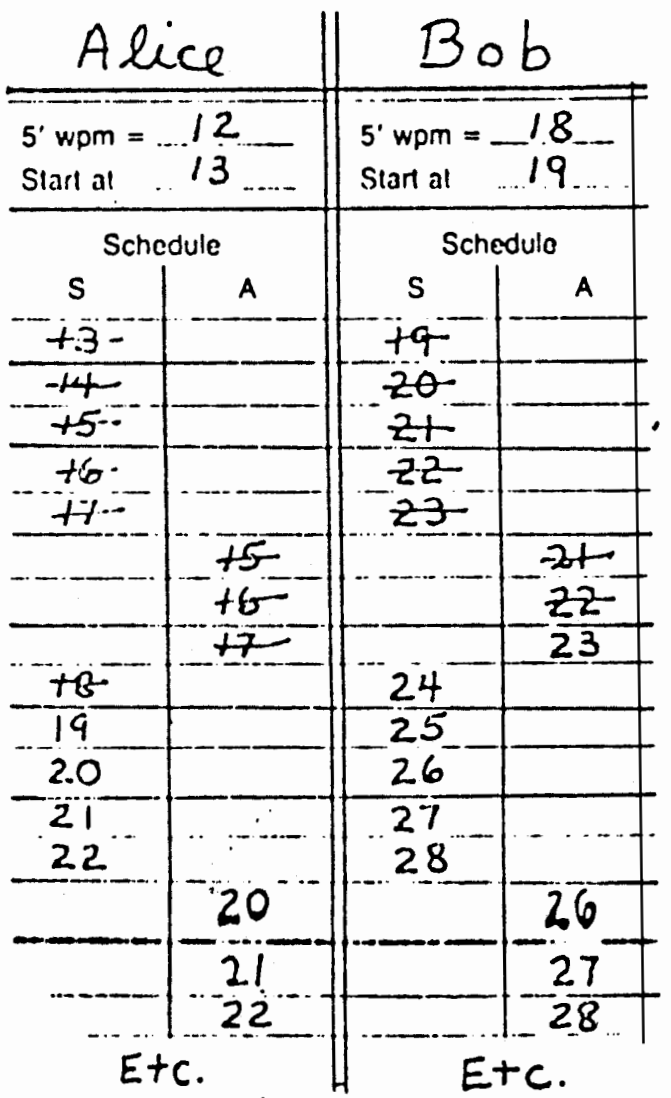


ERROR ALLOWANCES FOR PACED PRACTICE TIMINGS OF VARY ING DURATIONS

\begin{tabular}{|c|c|}
\hline Length of Timing & Errors Allowed \\
\hline $11 / 2$ & 3 \\
\hline $13 / 4$ & 4 \\
\hline 2 & 4 \\
\hline $21 / 4$ & 5 \\
\hline $21 / 2$ & 5 \\
\hline $23 / 4$ & 6 \\
\hline 3 & : \\
\hline $31 / 4$ & 7 \\
\hline $31 / 2$ & 7 \\
\hline $33 / 4$ & 3 \\
\hline 4 & 8 \\
\hline $41 / 4$ & 9 \\
\hline $41 / 2$ & 9 \\
\hline $43 / 4$ & 10 \\
\hline 5 & 10 \\
\hline $51 / 4$ & 11 \\
\hline
\end{tabular}




\section{IMING \#1}

Try several times, with eyes closed, to touch the tip of your nose 1th your fingertip. You never miss because the sensations of motion ind position in your muscles and joints inform you of the distance and lirection of your movements. The muscle sense is called kinesthesis-term that has no equivalent in everyday language. A11 skills involving movements, such as walking and talking, are based on kinesthesis.

The kinesthet1c sense, not the sense of touch, underlies skillful :yping. When muscular sensations instantly tell you, without looking, thether you have hit the correct key, you are on the road to expertness.

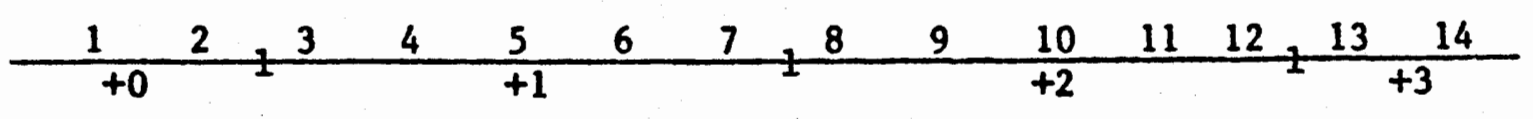

\begin{tabular}{lll} 
a & b & CW \\
\hline 3 & 28 & 1.3
\end{tabular}

$\begin{array}{lll}5 & 31 & 27\end{array}$

$8 \quad 34 \quad 42$

$11 \quad 36 \quad 56$

$\begin{array}{lll}14 & 39 & 70\end{array}$

$\begin{array}{lll}17 & 42 & 84\end{array}$

$\begin{array}{lll}19 & 45 & 97\end{array}$

$\begin{array}{lll}22 & 47 \quad 111\end{array}$

$\begin{array}{lll}25 & 50 \quad 126\end{array}$

Sy 1.52

St 6.2 


\section{PRETEST}

\section{IMING \#2}

\section{IEST, PAGE B27}

\section{5-2 (5)Minutes}

For many years it was wrongly supposed that the beginning typist should be required to imitate the expert by keeping eyes on copy. At :he start, you probably found it difficult and sometimes impossible to to so. Research in many skills, Including typewriting, has supplied the explanation or principle applicable to all of skill learning. The kinesthetic or muscle sense develops only after some learning has taken place on the basis of vision. At the start, you must look to learn.

How have you progressed in that regard? With each passing day do you less frequently watch your fingers and the keyboard?

GWDM

$\frac{a}{3}-\frac{b}{27} \quad \frac{C W}{13}$

$\begin{array}{lll}5 & 30 & 27\end{array}$

$\begin{array}{lll}8 & 33 & 41\end{array}$

$\begin{array}{lll}11 & 35 & 55\end{array}$

$\begin{array}{lll}14 & 38 & 69\end{array}$

$17 \quad 41 \quad 84$

$\begin{array}{lll}19 & 44 & 97\end{array}$

$\begin{array}{lll}22 & 47 & 111\end{array}$

$\begin{array}{lll}24 & 49 & 122\end{array}$

S飞 $6 \leqslant 54$ 


\section{POSTTEST}

JEST, PAGE B76

;' TIMING

GWPM

This essay explains a leading feature of the manuscript or report typing that starts in Lesson 59 in this book.

First, In this book the two terms--manuscript and report-are used Interchangeably. A manuscript is a handwritten or typewritten document, 13 distinguished from a printed copy. Many manuscripts, whether or not later printed, are reports.

Next, many reports include information from other sources. If $s 0$, It is both ethical and professional to mention the source of each such Item of information, as in the footnotes used for years in books. Foot-

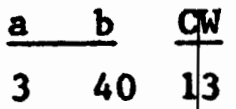
$4 \quad 42 \quad 22$ $7 \quad 4436$ 104751 $1350 \quad 65$ 145171 $1754 \quad 84$ $20 \quad 57 \quad 98$ notes, though, are time-consuming to type and costly to printe. A more $23 \quad 60 \quad 113$ $\begin{array}{lll}25 & 63 & 27\end{array}$ modern style, used in professional journals, does away with footnotes. Instead, the last name of the author and year of publication (of the ar$2865 \quad 141$ $3168 \quad 155$ $3471 \quad 170$ $\begin{array}{lll}37 & 74 & 184\end{array}$ $37 \quad 74 \quad 186$ Sy 1.55 st 5.9 report. A reference 11 st at the end of the report gives full publication data. 
You take straight copy timings regularly to determine whether you a b CW $344 \quad 13$ have gained in skill. For several months now, the ones whose scores you have been entering on your record form have been of five minutes duration. Also, the materials have always been of average difficulty. Why have test length and test difficulty been unchanged? The answer 18: because otherwise it would not be possible to detarmine how much of a change in your performance results from a change in skill and how much from a change in test length or test difficulty. Why five minutes? Because nearly all employment tests for typists use timings of that duration.

Why has a pair of timings been provided on important occasions and why have you been instructed to average your scores? First of all, a person's errors tend to vary from one time to the next. You cannot secure a dependable measure of stroking accuracy in merely one short test. Second, any score should ideally represent a person's typical performance, and typical means "on the average." 
The following procedures are recommended for use at Portland State Univert sity to maximize valid and reliable measurement of straight-copy typewriting proficiency in all typewriting classes and to provide a bases for the improvement of instruction.

Straight-copy speed (gross words per minute to the nearest tenth) and straight-copy accuracy (numbers of errors) will be used as criterion measures. Straight-copy typewriting is defined as word-for-word copying of printed or typed matter, without erasing and without format decisions by the typist.

TEST LENGTH: A ten minute sample of performance obtained by administering two five-minute timed writings.

REPORTING: Speed - count all words typed and divide by 10 . Student types 187 words on the first timing and 190 words on the secont timing $=377$ words $410=37.7$ wpm.

Accuracy - total errors in 10 minutes.

TEST DIFFICULTY: Copy difficulty must remain constant. Syllabic intensity range 1.51-1.57 and stroke intensity range 5.7-6.3 are recommended, yielding an average of 1.54 syllabic intensity and 6.0 stroke intensity, the exact averages for the vocabulary of written business communication.

TEST ADMINISTRATION:

1. A stopwatch should be used for all timed writings. Timings should be initiated via a 3-2-1 countdown; students begin typing at the count of 1 . Students should be reminded to stop immediately when they hear the stop signal.

2. Test timings should be administered at the beginning of the class period after the student has had about two minutes to check his machine via typing ordinary prose.

3. Keep test instructions constant--"Type at a comfortable rate, neither try to set a new record for speed nor slow down to an unnatural crawl in the hope of avoiding all errors."

4. Do not use the textbook as a source of timings. A different source will ensure unfamiliarity of copy. Do not use a timing more than once in any term.

5. Provide more copy than $90 \%$ of the students can finish in the time allowed. 
6. To check on equivalent difficulty for the pair of timings, counterbalance their administration: half work in A-B order, the other half in B-A order. Make certa in that the students head their papers with "Timing 1" or "Timing 2 " as the case may be.

7. Give everyone a minute or two to read the copy before the timing begins.

8. All test timed writings should be proofread at least twice and scored by the instructor. Always score the pair of timings--do not allow students to turn in the better of the two.

\section{PRETESTING:}

Pretesting procedures are the same as the preceding procedures, but involve several additional considerations.

1. Before the class begins, check all machines, set margins and tabs, set machine on double spacing, and insert paper in the machine. Turn off master switch to prevent students from typing until directions are given.

2. Explain the testing procedures to the students. Instruct them to put whatever they can on the page whether or not they have ever typed before. Tell them it is acceptable to type with one finger if necessary. Say: "If you make mistakes, ignore them. Continue with the next letfer or word."

3. Precede pretesting by demonstrating the use of the space bar, carriage return, and tab key for paragraphing.

4. Instruct students to type the copy line-for-line.

5. Have students write their names on the typescripts and pass them to the front of the room upon completion of the testing activity. It is advisable to count papers in order to make sure that each student has turned in all of his work.

"The attribution of changes in scores over time only to changes in skill requires that test length, conditions of administration, and difficul ty be constant. Otherwise, ambiguity results." (West, 1974) 
MEASUREMENT OF STRAIGHT COPY PROFICIEHCY

\section{Errors}

The following will be considered typographical errors for evaluation of straight copy timnd writings:

1. misstroke(s) within a word (circle the word--one error per word)

2. Incorrect punctuation following a word (circle preceding word)--count\$ as part of the word

3. more or less than one space between words (separate error)

4. only one space after sentence or colon (separate error)

5. A line extending more than a half inch Into the margin; a line ending (other than last paragraph) tco far inside the margin

6. an incorrectly divided word

7. ralsed cajtal

8. piled letters

9. shaded or too light leters (applies to manuals)

10. strike-over

11. Improper indention

12. Ine or portion of line omftted (count as one error, but deduct onfted words, from the word count): line or portion of line added (count as one error, but add words to the word count)

13. hands on wrong keys (one error)

14. Improper capitalization

15. Incorrect vertical spacing--if directions are to double space the tining, single spacing of the timing counts as one error; otherwise, cach instance op incorrect spacing counts as one error.

\section{Bord Count}

Three strokes or nore rounds to the next highest number of words (68 strokes Is equal to 14 words: 67 strokes is equal to 13 words). Counting ends with the Pinal leter or pimetuation that is typed. 


\section{REFERENCES}

Bryson, Jewell. "The Effects of Non-Machine Paced Methods vs the Strong Pacer in College Typewriting," Ed.D., University of Tennessee, 1965. DA(26), p. 4491.

Dupras, Arline. "Comparative Speed and Accuracy Achievements of High School Typewriting Students Taught by the 'Automated Instruction Touch Typing System' and by the Traditional

Teacher Directed Method," Ed.D., Boston University, 1973. DA (34), p. 1582 .

Hillestad, Mildred. Research: Process and Product. DPE Service Bulletin No. 1, 1977.

Johnson, Margaret. "The Effects of Skillbuilder Controlled Reader Training in Facilitating Skill Development in College Typewriting," Ed.D., North Texas State University, 1963. $D A(23), p .3258$.

Kl ine, Randall. A Study to Determine the Effectiveness of the Use of the Skillbuilder Controlled Reader as an Instructional Device in Developing Speed and Accuracy in Beginning Typewriting at the Secondary Level. Journal of Business Education, $1962, \underline{38}, 74$.

McAnally, Emmett. "An Evaluation of the Use of Mechanical Pacerls in Teaching Intermediate and Advanced College Typewriting," Ed.D., North Texas State University, 1966. DA(27), p. 294 $\mathrm{g}_{\mathrm{p}}$

Nie, Norman. Statistical Package for the Social Sciences, New York: McGraw-Hill, 1975.

Palmer, H.0. "Tachistoscope Training for Beginning Typing Students in a Secondary School," Ed.D., Oregon State University, 1955. Balance Sheet, 1956, 37, 200-203.

Perkins, Edward. "The Effectiveness of Controlled Reading-Rate Practice Techniques in the Development of Speed and Accuracy in Second Quarter College Typewriting, "Ed.D., Oregon State University, 1963. DPE Journal, 1964, $6,49-64$. DA(24), p. 3220 .

Rhodes, Ceorge S. Student Pacing for Pypewriting. Journal of Business Education, 1972, 47, 247-249.

Roscoe, John. Fundamental Research Statistics. New York: Holt Rinehart, and Winston, 1969. 
Shell, Walter. "Effectiveness of the Diatype as an Instructionall Device in First-Year Typewriting," Ph.D., Ohio State University, 1965. DA(26), p. 6565.

Tranquill, Cecil. "The Effectiveness of Individualized Pacing in Improving Typewriting Speed and Accuracy," Ed.D., University of Pittsburgh, 1965. DA(27), p.2018.

Trexler, Anna. "A Study to Determine the Effectiveness of the Gregg Pacesetter in Beginning Typewriting," Ed.D., University of Arkansas, 1973. DA(34), p. 2450.

West, Leonard J. Acquisition of Typewriting Skills--Methods and Research in Teaching Typewriting, New York: Pitman, 1969.

West, Leonard J. Implications of Research for Teaching Typewriting. DPE Research Bulletin \#4, 1974.

West, Leonard J. Design and Conduct of Educational Surveys and Experiments. DPE Service Bulletin \#2, 1977.

West, Leonard J. Principles and Procedures for Teaching Typwriting. Monograph \#1, Harcourt Brace Jovanovich, 1979.

West, Leonard J. Modern College Typewriting--A Basic Course. New York: Harcourt Brace Jovanovich, 1977.

West, Leonard J. Instructor's Manual for Modern College Typewriting--A Basic Course. New York: Harcourt Brace Jovanovich, 1977

West, Leonard J. Personal interview, June 1979.

Winger, Fred. "The Determination of the Significance of Tachistoscope Training in Word Perception as Applied to Beginning Typewriting Instruction," Ed.D., University of Oregon, 1951. Journal of Business Education, 1952, 28, 118. 